\title{
Study on industrial structure adjustment and low-carbon economic development
}

\author{
Jing Zhang \\ Xi'an International University, Xi'an, 710077, China
}

Keywords: industrial structure; low-carbon economy; relationship; path

\begin{abstract}
Based on analyzing low-carbon economy according to current situation, this paper analyzes the relationship between industrial structure adjustment and low-carbon economy and discusses the paths for industrial structure development under the mode of low-carbon economy from the following aspects: creating new low-carbon industrial chain; transforming high-carbon industry from high energy consumption to low energy consumption; developing new low-carbon industry; enhancing solution, research and development of low-carbon key technology; establishing and perfecting legal system.
\end{abstract}

\section{Introduction}

Low-carbon adjustment of industrial structure is an important move to develop low-carbon economy and promote Chinese economic growth mode. The development situation of low-carbon economy urgently requires adjustment of the structure dominated by high-carbon industry. On the one hand, adjusting industrial structure to low carbon is an internal requirement of low-carbon economy. On the other hand, the development of low-carbon economy also promotes paths and methods for enterprise transformation and upgrade. Under such situation, it is especially important to discuss the paths of industrial structure development under the mode of low-carbon economy.

\section{Interpretation of low-carbon economy under new situation}

Low-carbon economy is a new economic mode, which can promote economic development in a good and fast way and avoid climate warming and environmental pollution caused by energy consumption. It is characterized by low energy consumption, low pollution and low discharge.

\section{Essence of low-carbon economy}

The essence of low-carbon economy is to change existing energy consumption view, economic development mode and traditional life style, reflected in the following aspects in detail:

Firstly, effectively utilize primary energy and take advantage of high and new technology to develop pollution-free clean energy, such as wind energy, solar energy and geothermal energy. Synchronous improvement of natural environment is the center of low-carbon economy. But, in most developed countries, primary energy consumption accounts for the absolutely major proportion. High energy consumption, serious pollution and large amount of greenhouse gas emission accelerate deterioration speed of natural environment.

Secondly, value "quantity" change in economic field and stress transformation of economic growth mode through improving product quality. It owns very obvious features, such as sustainability and economic structural adjustment. To develop low-carbon economy in developing countries, economic growth mode must be changed.

Thirdly, reinforce development of low-carbon economy, and change life style of the public. Developing new energy is not equal to moving toward low-carbon economy. Moving toward low-carbon economy does not mean to eliminate manufacturing industry with high energy consumption. People' life style and consumption view should be considered. Developed science and technology bring many convenient techniques, such as electrification, mechanization and automation. These advanced techniques make people greatly depend on energy and power. Meanwhile, large energy consumption, environmental pollution and climate warming are also caused. 
Key of low-carbon economy - to develop low-pollution and low-energy low-carbon economy

Currently, low-carbon technology is mainly applied in some traditional departments. Exploration and development of gas layer, oil and gas resources, acquisition and burial of carbon dioxide and development of new energy also need to reduce greenhouse effect.

\section{New development brought to economy by low-carbon economy}

In the $7^{\text {th }}$ national conference on environmental protection, Premier Li Keqiang refined low-carbon economy as a high-cost and high-input new economy. Low-carbon economy has sustainable development nature and can effectively promote continuous and healthy development of other fields. It is necessary to consider long-term benefits during development of low-carbon economy. For example, in such fields of low-carbon industry, low-carbon agriculture, carbon sequestration transaction and relevant industries, rapid economic growth cannot be seen in a short term and enterprise income is also low. But, these are well-operated low-carbon economic modes and new economic growth points.

\section{Relationship between industrial structure adjustment and low-carbon economy}

Industrial structure refers to the composition of each industry in an economic entity. Apart from the primary industry, secondary industry and tertiary industry, each industry is subdivided into many industries. Local economic development degree can be seen from industrial composition in the economic entity and marks economic development stage of a region.

\section{Requirements of low carbon economy for industrial structure adjustment}

Low-carbon economy puts forward three requirements for industrial structure:

Firstly, industrial structure rationalization. Industrial structure rationalization mainly refers to enhancing exchange and cooperation among each industry and strengthening coordination ability. It is required to stick to developing low-carbon economy, transform economic growth mode of high-energy and high-pollution industries, increase the proportion of low-carbon industry in total industries and gradually make each industry rationalized.

Secondly, high industrial structure. High industrial structure mainly refers to transformation of industrial structure from low to high. The products gradually develop to high-processing degree from low-processing degree. It is a dynamic changing process. To make industrial structure become high, it is required to follow industrial structure evolution rule, promote industrial structure to change from low to high according to low-carbon principle, gradually eliminate high-energy and heavy-pollution industries with low resource utilization rate and effectively improve the proportion of low-carbon industry.

Finally, low-carbon industrial structure. Low-carbon industrial structure is the core of developing low-carbon and also the root of solving low-carbon. The industries with low energy consumption and light pollution are the foundation of developing low-carbon industry. Protecting environment and reducing greenhouse effect are the final objective of developing low-carbon industry.

\section{Effects of industrial structure adjustment on low-carbon economy}

Environmental pollution degree and resource consumption play a decision role for development trend of industrial structure. Only through continuously optimizing industrial structure, low-carbon economic development can be promoted; industrial imbalance situation can be adjusted; healthy and rapid economic development can be promoted.

Firstly, industrial carbon emission level is decided by the proportion of the three main industries. There are great differences in matter input in different industries. Under existing technical conditions, wastes generated in the production process are different in different industries. In the industry, for pharmacy and communication industry with low input in mineral substances and low energy consumption, cement industry and iron \& steel industry will consume more energy and thus lead to more pollution.

Different industries also need different elements in the development process. This also leads to the differences in production factors. So, different industries have different resource input and consumption. For high and new technology industry, immaterial input such as high and new technology and intellectual property account for most output share. The input in energy and raw 
materials is very small. In planting industry, land value occupies a very large proportion in the input.

Therefore, we call technology-intensive industry with high technical content and low energy consumption high technology industry and call the industry with low technical industry similar to planting industry resource-intensive industry. It thus can be seen that it is required to transform economic growth pattern, develop high and new technology industry with low resource input, low energy consumption and light pollution, and gradually reduce the proportion of resource-intensive industry in order to well develop low-carbon economy. So, an important factor deciding resource consumption and greenhouse gas emission level of an economic entity is economic structure.

Secondly, industrial structure optimization and upgrade can effectively promote development of low-carbon economy.

The successful experience of western developed countries in developing low-carbon economy tells us that highly optimized structure can greatly reduce cost and resource input needed by economic growth. Optimizing industrial structure can effectively decrease the dependence degree of the industry on resources and energy. Meanwhile, developing more high and new technology industries also contributes to promoting optimization and upgrade of industrial structure and realizing transformation of the industry to high industrial structure from low industrial structure. Optimizing and adjusting industrial structure, and reducing the dependence on resources and energy on the basis of the development idea of low carbon economy can fundamentally reduce environmental pollution and ecological destruction.

\section{Paths of industrial structure development under the mode of low-carbon economy}

Under the background of global warming, low-carbon economy based on low energy consumption and low pollution has become a common choice of governments in each country. Under the era background of low-carbon economy, adjustment, optimization and upgrade of industrial structure have become an important topic. The following paths can be tried to boost industrial structure adjustment under the mode of low-carbon economy:

To create a new low-carbon industrial chain under the guidance of low carbon economic development

In current stage, value distribution of industrial chain still tends to resource-based enterprises. Making a new low-carbon industrial chain under the guidance of low carbon economic development aims to change such distribution status. The following two aspects should be made in detail:

Firstly, shorten high-carbon industrial chain and realize "low-carbon" upstream and downstream industries of high-carbon industry. High-carbon industry is mainly composed of energy, automobile, steel, traffic, chemical industry and building materials. Currently, the development of low-carbon industry in china does not form a systematical and complete industrial chain. High-carbon industrial chain still occupies a large proportion. Low-carbon upstream and downstream industries or reduction of carbon emission will become an important direction to drive modern industrial system innovation and low-carbon economic development.

Secondly, adjust high-carbon industrial structure and gradually promote the proportion of low-carbon industry. Currently, high-carbon industry dominated by "heavy industry" occupies a large proportion in industrial structure of the whole national economy. So, it is required to start with reduction of the proportion of high-carbon industry in national economic structure to promote industries and products to extend toward both ends of the profit curve, i.e. extending toward the frontend, form independent intellectual property right from ecological design; extending toward the rear end, form brand and sales network, improve core competitiveness and finally make industrial structure of national economy tend to the standards of low-carbon economy.

To energetically drive transformation of high-carbon industry to low energy consumption from high energy consumption

Chins is now in industrialization and urbanization course. High-carbon industry characterized by heavy chemical industry still presents rapid growth trend. But, relative to low-carbon industry, 
carbon emission in high-carbon industry is relatively high. As a developing country, industrialization stage is an inevitable important stage in development. Meanwhile, the possibility of greatly reducing heavy chemical industry is very small. Thus, under the guidance of low carbon economic development idea, it is required to achieve transformation of high-carbon industry from high energy consumption to low energy consumption and reduce carbon emission of unit GDP of these industries through improving resource utilization rate in energy transformation link and lowering energy consumption in heavy chemical industry. Driving Chinese industry to change to low energy consumption from high energy consumption has become an inevitable direction of Chinese industrial transformation. It is necessary to practice it in practice.

\section{To develop new low-carbon industry}

Under the call and support of national strategy, rapid development of new low-carbon industry is an important approach to drive development of low carbon economy. In current stage, new low-carbon industry full of vigor and vast development prospect mainly includes thermal power emission reduction, new energy automobile, building energy efficiency, industrial energy saving and emission reduction, circular economy, resource recovery, environmental protection equipment and energy saving materials etc. it is required to carry out clean production, adopt new energy and renewable energy sources, gradually weaken fossil resource with high emission, and construct perfect low-carbon technology research and development system, low-carbon energy system and low-carbon industrial structure through developing new low-carbon industry.

\section{To enhance solution, research and development of low-carbon key technology}

Research and development of low-carbon technology provide important guarantee for the industry to turn to low-carbon industry from high-carbon industry. Currently, EU has inputted large quantities of manpower and funds in research and development of low-carbon technology to research and develop cheap, clean, efficiency and low-emission world-class energy technology in order to seize the commanding height of low-carbon energy technology. Low carbon economy develops late in China. As national the development strategy of low carbon economy is implemented, it is badly necessary to focus on new energy, renewable energy sources, oil and gas resources, greenhouse gas emission control technology and clean and efficient coal utilization technology to solve technical difficulties, work out long-term development plan to enhance independent research and development of low-carbon key technology and develop new and efficient low-carbon technology.

\section{To establish and perfect legal system}

It is necessary to perfect supporting legal system for low-carbon industry, innovate in policies and regulations and combine outstanding problems to construct flexible market mechanism and strict legal system. It is required to form legally binding force for high-carbon industry through enhancing legislation, supplementing and perfecting existing legal and regulations, detail renewable energy sources and environmental protection laws, deeply implement these laws in practice and drive the whole society to ale the way of developing low-carbon economy.

\section{Conclusions}

Developing low-carbon economy is imperative. Driving industrial structure adjustment is also extremely urgent. It is required to conform to the development trend of low-carbon economy, grasp current new opportunity of international industrial transfer, explore new paths to drive low-carbon economic development and industrial structure adjustment, promote industrial structure transformation and upgrade through low-carbon technical innovation, ensure smooth implementation of industrial structure adjustment through perfecting laws and regulations on low-carbon industry, rapidly develop new low-carbon industry, gradually construct low-carbon industrial system, and make industrial structure low-carbon adjustment matched with low-carbon economic development so as to better promote implementation of low-carbon economic development strategy. 


\section{Acknowledgments}

This paper is social science fund program of Xi'an in 2014. Title: Study on current situation of carbon emission in Xi'an and low-carbon economic development strategy. Project No.: 14IN16

\section{References}

[1] Yao Min, Cai Shaohong, Study on industrial structure adjustment under the background of low-carbon economy [J]. Theory Discussion, 2012, 06:94-97

[2] Jia Lijiang, Fan Decheng, Wu Yanjun, Study on industrial structure adjustment under the background of low-carbon economy [J]. Inquiry into Economic Issues, 2013, 02:87-92

[3] Zhao Huining, Yu Weiyang, Study on industrial structure adjustment and optimization in Hebei province under the perspective of low carbon [J]. Journal of Hebei University Of Economics and Trade, 2013, 03:75-77

[4] Fang Xiaoxiang, Zhang Qilei, Li Jisheng, Industrial structure adjustment in Anhui Province under low-carbon background [J]. Times Finance, 2013, 14:97

[5] Yan Chenglei, Liu Chao, Li Yuxin, Wu Haotian, Wang Na, Study on industrial structure adjustment in Heilongjiang Province under low-carbon background [J]. Market Modernization, 2013, 18:131

[6] Yin Xiujuan, Low carbon economy and industrial structure adjustment in Qinghai [J]. Special Zone Economy, 2012, 10:175-177 